\title{
Caracterização de Cicatrizes de Deslizamentos por Processamento de Dados TM Landsat em Caraguatatuba - SP
}

\author{
Marcelo Francisco Sestini' (sestini@geo.funcate.org.br) e Teresa Gallotti Florenzano² \\ 'Centro de Previsão de Tempo e Estudos Climáticos - INPE \\ Rod. Presidente Dutra km 40, CEP 12630-000, Cachoeira Paulista, SP, BRA \\ 2Observação da Terra - INPE, São José dos Campos, SP, BRA
}

Palavras-chave: cicatrizes de deslizamentos, MNT, técnicas de processamento de imagens, TM Landsat 5, SIG.

\section{RESUMO}

O objetivo deste trabalho é identificar e caracterizar cicatrizes de deslizamentos através de dados TM Landsat 5. A área de estudo é um setor da Serra do Mar, no município de Caraguatatuba (Estado de São Paulo), a qual é susceptível a esses processos. Foram testadas composições com bandas TM Landsat, bem como composições com imagens resultantes de razão entre bandas e resultantes de Transformação por Componentes Principais (TCP), verificando-se a contribuição dessas ao realce das feições, principalmente cicatrizes de deslizamentos. Estes dados foram cruzados com outros extraídos de Modelo Numérico de Terreno (MNT). Os resultados se apresentaram consistentes com áreas susceptíveis a deslizamentos, conforme a literatura.

Keywords: landslide scars, Digital Elevation Model, image processing technics, TM Landsat 5, GIS.

\begin{abstract}
The objective of this work is to identify and to characterize landslide scars using TM Landsat 5 data. The study area is a sector of the Serra do Mar, in the Caraguatatuba municipality (São Paulo State, Brazil), which is favorable for these processes. Landsat TM composites were tested, as well as resultant images of the ratio bands and principal component transform, verifying the contribution of these processing to the landslide scars enhancement and feature distinction. These data were integrated to the digital elevation model. The results obtained are coherent with landslide areas and the literature.
\end{abstract}




\section{INTRODUÇÃO}

Os deslizamentos têm como característica produzir cicatrizes com uma geometria definida (Figura 1), formada pela cabeceira (onde se inicia o escorregamento), pelo corpo (ao longo da faixa afetada pela remoção e transporte de material) e pela base (onde se deposita o material transportado), conforme Zaruba e Mencl (1982), Hansen (1984) e IPT (1989). Estes tipos de processos se desenvolvem ao longo dos cursos de drenagem e sobre as encostas, transportando carga proveniente de material erodido nos canais de drenagem e também de escorregamentos adjacentes a esses canais (terraços, tálus e colúvio). É freqüente originarem-se em cabeceiras de drenagem situadas em declives maiores que $20^{\circ}$, formando, a jusante, cone de detritos.

Vários trabalhos para a detecção de deslizamentos utilizam fotografias aéreas (Patton, 1988; Dikau, 1989; Gao e Lo, 1995), devido à resolução espacial mais fina, mas há trabalhos realizados com a utilização de dados TM Landsat com resolução de $30 \mathrm{~m}^{2}$, como McKean et al. (1991), Walsh e Butler (1997) e outros.

A detecção de cicatrizes em dados de sensoriamento remoto pode ser expressa pela seguinte relação:

$$
N=f(R, A)
$$

onde $\mathrm{N}$ é o número de cicatrizes possíveis de serem identificadas, R é a resolução espacial do sensor, Aé a área das cicatrizes e f é uma função direta.

As características de resolução (espacial, temporal, espectral e radiométrica) dos sistemas sensores orbitais, bem como o caráter sinóptico dos dados obtidos por esses sistemas permitem observar as feições da paisagem relacionadas aos processos de movimentos de massa (King e Delpont, 1993; Walsh et al., 1998).

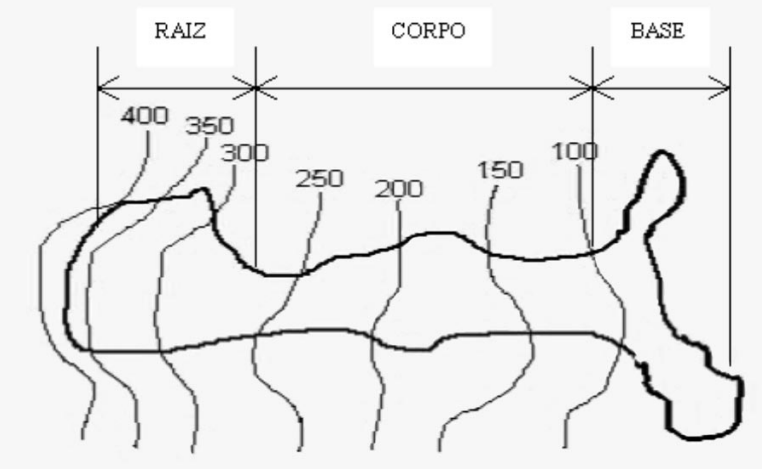

Figura 1. Esquema dos componentes de uma cicatriz de deslizamento (linha espessa) superposto às curvas de nível. Fonte: modificado de Zaruba e Mencl (1982, p. 81).
Dados de sensoriamento remoto orbital podem ser utilizados para estudos de movimentos de massa tanto na detecção direta das consequiências destes processos (cicatrizes devido à remoção da cobertura vegetal e exposição de camadas subsuperficiais do solo e deposição de material transportado formando leques de detritos) como através da identificação de indicadores. Estes indicadores referem-se às mudanças na resposta da cobertura vegetal, devido a escorregamentos anteriores (diferença na densidade e tipo de vegetação), uso da terra (cortes de estradas ou remoção de vegetação por ação antrópica em áreas propícias a deslizamentos), morfologia (formas de vertentes) e dissecação do relevo (King e Delpont, 1993; Berger, 1996; Romanovskii et al., 1996). A remoção de cobertura vegetal e das camadas superficiais do solo por processos naturais ou ação antrópica resulta em mudanças nas características espectrais da superfície, que são detectadas por sistemas sensores.

As diferenças de comportamento espectral entre o solo, feições antrópicas e a vegetação e dentro da própria vegetação (tipo e porte desta) são observadas nas bandas do visível e do infravermelho de dados TM Landsat. Diferenças entre cicatrizes apresentando solo ou rocha expostos e cicatrizes com retomada da vegetação (gramíneas, samambaias) podem também ser detectadas pelos sensores. Assim, processamentos como, por exemplo, razão entre bandas e Transformação por Componentes Principais (TCP) destacam essas diferenças e servem como indicadores de processos geomorfológicos e informam sobre características de ocupação do solo. (Drury, 1993; Walsh et al., 1998).

No caso de deslizamentos, a remoção da cobertura vegetal e consequiente exposição do solo ou rocha e deposição de material transportado ao longo da vertente à jusante imprimem diferenças de tonalidade, cor, matiz e textura na cena imageada, além de apresentarem formas específicas, o que permite a interpretação direta destas feições (McKean et al., 1991; Gao e Lo, 1995). Já as características topográficas e morfológicas (depressões provocadas por estes eventos ou drenagem pouco espaçada) e da cobertura vegetal (inclinação ou remoção de árvores, provocando diferenças de textura na imagem devido à variação abrupta de tonalidade), sugerem a ocorrência desses processos na cena imageada. As variações na textura da vegetação são melhor percebidas em dados de sensores com resolução espacial mais fina, como fotografias aéreas (McKean et al., 1991; Augusto Filho, 1994; Belsher, 1997; Walsh e Butler, 1997).

As formas das cicatrizes geradas por deslizamentos são geralmente elípticas ou cônicas e, quando recentes, observa-se a cabeceira ou raiz (onde o material é removido, expondo o solo ou rocha), o corpo (porção ao longo da qual o material é transportado) e a base, onde há depósito do material removido (Soares e Fiori, 1976; Zaruba e Mencl, 1982; 
Hansen, 1984; Patton, 1988; IPT, 1989). Essas cicatrizes se desenvolvem, geralmente, em setores côncavos das vertentes, ao longo de linhas de drenagem ou em torno de alterações antrópicas (estradas, por exemplo), estendendose sobre alta ou média vertente (em declives maiores que $20^{\circ}$ ) e depositando o material removido em pontos de baixa vertente e vales, onde há, por conseqüência, formação de tálus e/ou leques de deposição, alterando a topografia (Zaruba e Mencl, 1982; Patton, 1988; Gao e Lo, 1995; Fernandes e Amaral, 1996; Sestini, 1999). Dessa forma, através da interpretação de elementos diretos e indiretos podese identificar pontos de um terreno susceptíveis a deslizamentos.

Entretanto, McDermid e Franklin (1994) chamam a atenção para a limitação de dados TM Landsat, devido à semelhança de forma e de resposta espectral, existente entre certas feições relacionadas ao uso do solo com as resultantes de processos naturais. A interpretação pode ser prejudicada tanto pela maneira como se organiza o fenômeno (a forma e padrão de alguns fenômenos distintos podem ser semelhantes) como pela existência de obstáculos à detecção desse fenômeno, devido à resolução espacial do sensor ou semelhança de comportamento espectral entre objetos diferentes. Como nem sempre os processamentos de imagens permitem distinguir nitidamente as diferenças entre formas resultantes de causas distintas, o uso de dados obtidos a partir do Modelo Numérico de Terreno (MNT) leva a uma abordagem mais segura, pois fornecem detalhes da topografia (McDermid e Franklin, 1994).

\section{ÁREA DE ESTUDO, MATERIAIS E MÉTODOS}

A área de estudo localiza-se a $23^{\circ} 37^{\prime} 55^{\prime \prime}$ - 23 $44^{\prime} 50^{\prime \prime}$

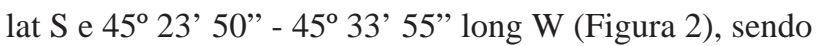
enfocada a compartimentação de relevo escarpado e com elevada dissecação, caracterizada pela ocorrência de intensos processos morfogenéticos, entre os quais os deslizamentos (Almeida, 1964; Ab'Saber, 1966; Cruz, 1974; Projeto RADAMBRASIL, 1983; IPT, 1989), que são observados nas áreas de maior energia do relevo através de suas cicatrizes.

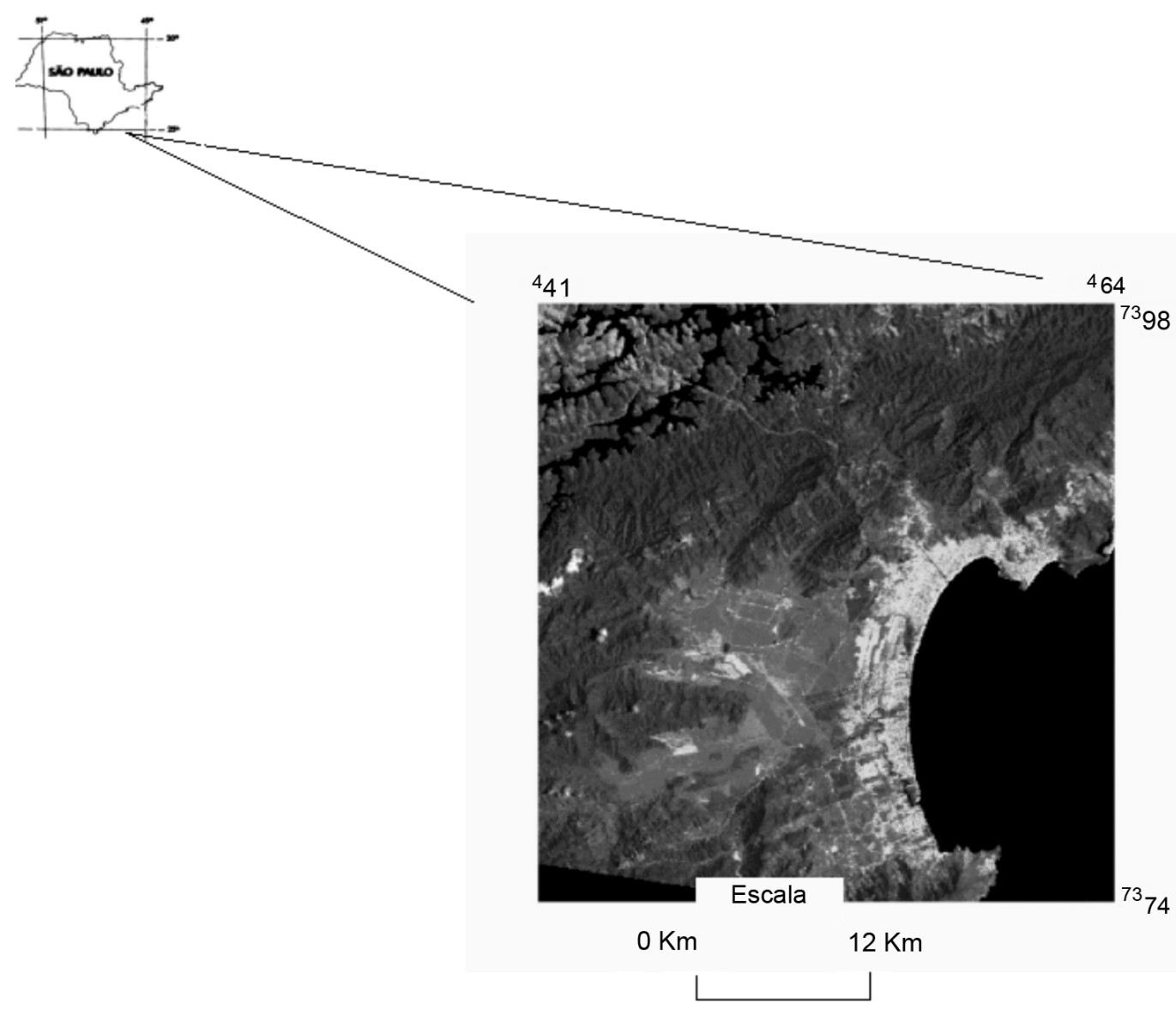

Figura 2. Localização da área de estudo. 


\section{Seleção da área de estudo e coleta de dados}

A área de estudo foi selecionada por apresentar susceptibilidade a deslizamentos, disponibilidade de dados, trabalhos realizados anteriormente relacionados ao tema (Cruz, 1974; Okida, 1996) e facilidade de acesso. Através de pesquisas em bibliotecas, arquivos de jornais, em boletins técnicos e mapas de risco elaborados pela Comissão de Defesa Civil (COMDEC), Instituto Geológico (IG), Instituto de Pesquisas Tecnológicas (IPT) e Secretaria do Meio Ambiente (SMA), coletaram-se dados referentes a deslizamentos na área de estudo. Estes dados serviram para datar os eventos e também caracterizar seu tipo (queda de blocos, deslizamentos etc.) e áreas de ocorrência.

Coletaram-se, junto ao Centro Tecnológico de Hidráulica (CTH, 1997), dados de precipitação a partir de 1985, visando a seleção de imagens TM Landsat (não existiam à época deste trabalho, dados referentes a 1984, ano de início da geração de dados TM).

Analisando-se todos os dados coletados, a disponibilidade e qualidade das imagens, foram selecionadas para o desenvolvimento deste trabalho aquelas referentes aos anos de 1988 e 1996, nos quais verificou-se elevada precipitação, principalmente para este último. Verificou-se, ainda, através dos boletins do IPT e IG, que o ano de 1996 apresentou elevados valores de pluviosidade acumulada. Com relação à pluviosidade acumulada, deve-se salientar que a expansão de áreas antropizadas tem aumentado a ocorrência e o impacto de deslizamentos e reduzido o valor de pluviosidade acumulada, anteriormente estabelecido como sendo deflagrador de deslizamentos (120 mm em três dias), segundo Nunes e Modesto (1992 e 1996).

Foi realizada então uma interpretação preliminar das imagens TM. A imagem de 1996 foi selecionada para a interpretação e análise das cicatrizes de deslizamentos, pois a de 1988 corresponde a baixo ângulo de elevação solar e o sombreamento encobre vários setores da área de estudo, impedindo a extração de informações de interesse. Este fato inviabilizou um estudo multitemporal do fenômeno, pois levaria a uma análise tendenciosa das áreas susceptíveis a deslizamentos.

\section{Processamento das imagens TM}

Neste trabalho aplicaram-se processamentos de realce de feições de interesse aos objetivos do estudo realizado, facilitando a interpretação destas feições. Previamente realizaram-se pré-processamentos, visando a redução de efeitos atmosféricos e o geo-referenciamento.

\section{Pré-processamentos}

Para a redução de efeitos atmosféricos, procedeu-se à subtração de níveis de cinza (Schowengerdt, 1983; Novo, 1992; Drury, 1993; Richards, 1995; Walsh et al., 1998), no qual foram tomadas amostras dos pixels de sombras, da represa de Paraibuna e da porção do mar mais afastada do continente, por ser menos contaminada por sedimentos.

Para a correção geométrica procedeu-se ao geo-referenciamento baseado em registro entre mapas e imagens (Richards, 1995). Os pontos de controle (como encontros de drenagem, estradas e picos de interflúvios e colinas) foram selecionados na carta topográfica e aplicou-se um polinômio de $1^{\circ}$ grau, adequado às transformações necessárias para a correção geométrica das imagens utilizadas (Netgis, 1997).

\section{Seleção de bandas e obtenção de composições coloridas}

Neste trabalho, testaram-se composições coloridas que destacam as feições de interesse com base nas respostas espectrais dos alvos mostrados na Figura 3 e na análise da estatística das imagens, como a média, variância-covariância e correlação entre bandas. As variáveis estatísticas das imagens foram obtidas automaticamente. Dessa forma, os parâmetros estatísticos subsidiaram a escolha das bandas destinadas à geração de composições coloridas e aos processamentos, além de auxiliarem a análise dos resultados obtidos.

De modo geral, as melhores composições são as obtidas com bandas de alta variância (pois destacam a textura) e de baixa correlação entre si (para evitar redundância de dados), o que varia conforme o comportamento espectral dos objetos da cena imageada (Figura 3). Deve-se observar, entretanto, que a correlação pode ser útil para o realce de feições erosivas (estendendo-se a cicatrizes de deslizamentos) e de ocupação (Valério Filho e Pinto, 1986; Florenzano, 1993).

\section{Técnicas de realce de imagens}

Os processamentos aplicados neste trabalho foram selecionados com base na literatura e objetivaram destacar tanto as feições diretamente ligadas aos deslizamentos (cicatrizes) como as feições indiretamente relacionadas a esses processos (características de unidades de relevo, como a forma de vertentes e a dissecação, feições antrópicas etc.). Estes processamentos incluem a ampliação linear de contraste (ALC), a razão entre bandas e a Transformação por Componentes Principais (TCP). 


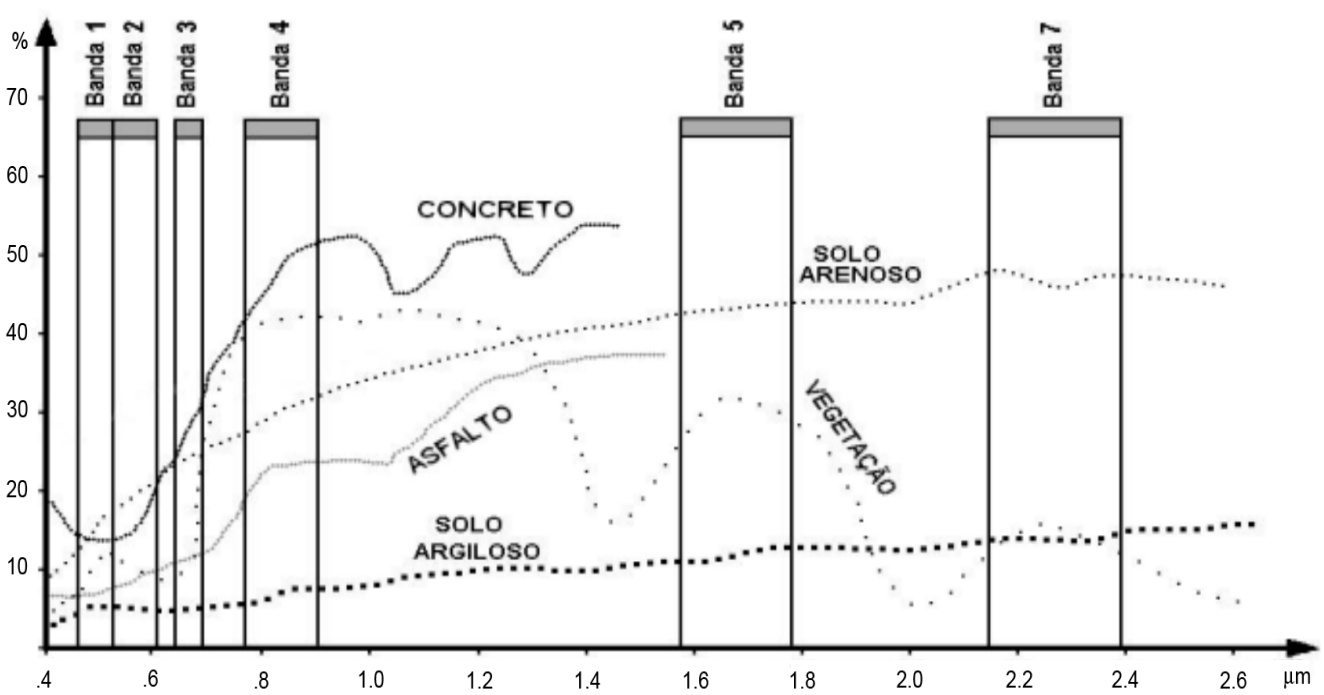

Figura 3. Bandas do TM e comportamento espectral de alguns objetos. Fonte: adaptada de Bowker (1985).

\section{Ampliação linear de contraste (ALC)}

O ALC é um procedimento usual de realce linear, através do qual se expandem os valores dos níveis de cinza redistribuindo-os em toda a escala de 0 a 255 . O realce linear possibilita um aumento na variância dos dados e, conseqüentemente, um melhor contraste. Os valores adotados variam conforme a banda e outras características da imagem (Richards, 1995). Aplicou-se o ALC nas bandas selecionadas das imagens de 1996 e nas imagens resultantes da razão entre bandas e do Normalized Difference Vegetation Index (NDVI).

\section{Razão entre bandas}

A razão entre bandas permite discriminar diferenças sutis existentes no comportamento espectral de diferentes alvos. Observando-se o comportamento espectral dos alvos de interesse, selecionaram-se as bandas que cobrem valores máximos e mínimos de reflectância (bandas pouco correlacionadas) e que expressam o gradiente da curva espectral dos objetos de interesse, proporcionando, assim, o realce desses. Este processamento tem a desvantagem de causar o exagero de ruídos, perda de textura devido à atenuação do sombreamento e a não distinção entre alvos com comportamento espectral similar. Se alvos possuem albedos diferentes (expressos na imagem pela intensidade de brilho do nível de cinza), mas propriedades espectrais inerentes similares, ao se fazer a razão de bandas esses alvos acabam por serem expressos de forma semelhante ou igual, tornando-se indistintos, ao passo que nas bandas originais são perfeitamente distinguíveis devido à diferença no albedo
(Mather, 1987; Crosta, 1993; Drury, 1993).

Um dos tipos de razão entre bandas é o Índice de Vegetação com Diferença Normalizada ou NDVI (do inglês: Normalized Difference Vegetation Index), que realça o contraste entre áreas vegetadas e com escassa ou nenhuma vegetação. A razão entre as bandas TM 4 e TM 3 coloca em evidência diferenças dentro da cobertura vegetal, por enfatizar as variações existentes nos picos das faixas do infravermelho (TM 4) e do visível (TM 3) (Mather, 1987; Crosta, 1993; Drury, 1993). Como os solos e superfícies construídas têm resposta alta a partir da banda 3 e a vegetação apresenta um pico na banda TM 4 (infravermelho próximo), essas operações aumentam o contraste entre esses tipos de superfícies e a variação e densidade da cobertura vegetal, o que pode ser indicador de processos geomórficos (McKean et al., 1991; Drury, 1993; Crosta, 1993; Walsh et al., 1998).

A razão da banda TM 5 pela TM 7 realça feições relativas a solos argilosos. Os efeitos rotacionais das moléculas hidroxiladas (como $\mathrm{Al}-\mathrm{OH}$ e $\mathrm{Mg}-\mathrm{OH}$ ) associados à argila provocam uma faixa de absorção na banda TM 7. Ao se fazer a razão entre as bandas TM 5 e TM 7 tem-se um destaque de solos argilosos, aparecendo estes em níveis de cinza claros. Deve-se observar que o resultado dessa operação é influenciado pela interferência de outros alvos. Uma camada delgada de vegetação, por exemplo, interfere no valor resultante da operação, pois a radiância captada pelo sensor integra também a resposta da vegetação, contaminando, conseqüentemente, o pixel (Drury, 1993).

Já para o asfalto e concreto as curvas apresentam um baixo valor de reflectância na faixa correspondente à banda TM 1 e alto valor para a banda TM 4. A diferença entre 
ambos é que o asfalto possui valor de reflectância mais baixo que o concreto, além deste último apresentar feições de absorção para as bandas 1 e 4 , como pode-se observar na Figura 3.

Assim, efetuaram-se neste trabalho as razões 5/7, 4/3, 4/1. Com este triplete testaram-se as melhores composições RGB, com a finalidade de destacar setores com escassa ou nenhuma vegetação (referentes a feições antrópicas e às cicatrizes de deslizamentos), diferenças entre solo exposto (dada pela razão 5/7, já que o predomínio de solos é argiloso) e área construída (dada por 4/1). Também analisou-se o uso de NDVI.

\section{Transformação por Componentes Principais (T⿱CP)}

A Transformação por Componentes Principais visa a redução da dimensionalidade dos dados e a remoção da redundância de informações oferecendo uma maior separabilidade de alvos. A natureza multidimensional (representada pelas bandas) dos dados de sensoriamento remoto pode ser expressa sob a forma de um espaço vetorial, no qual um determinado pixel é posicionado em um sistema de coordenadas, correspondendo essa posição a um vetor que representa o valor ponderado do brilho deste pixel, considerando-se todas as bandas do espaço multiespectral. $\mathrm{O}$ valor do brilho de um pixel numa banda componente principal é resultante da ponderação do valor do brilho que este pixel possui em cada banda original.

$\mathrm{O}$ algoritmo efetua a TCP a partir da variância e covariância das bandas originais, e do coeficiente de correlação entre elas, realizando uma transformação linear das bandas originais em novas variáveis, que são as componentes principais (CPs), sendo estas últimas a combinação linear das bandas originais. A primeira $\mathrm{CP}$ retém a maior proporção da variância total dos dados, diminuindo esta proporção para as componentes seguintes (Crosta, 1993; Drury, 1993; Richards, 1995).

Neste trabalho foram geradas as imagens CPs a partir das bandas 1, 2, 3, 4, 5 e 7 da imagem TM de 1996. Com as imagens CPs geradas foram testadas várias composições coloridas, de forma a obter o melhor resultado visual para a interpretação dos alvos de interesse.

\section{Interpretação de dados de Sensoriamento Remoto}

As imagens TM resultantes dos processamentos aplicados, bem como as fotografias aéreas, foram interpretadas com base nos elementos de análise de imagens - textura, tonalidade, cor, forma, padrão e contexto - (Veneziani e Anjos, 1982; Lillesand e Kiefer, 1994; Rydén, 1997) e conside- rando-se, também, as características espectrais das respostas dos objetos nas diferentes composições testadas. Além desses elementos, utilizou-se a estereoscopia (Verstappen, 1977).

Neste trabalho analisaram-se as fotografias aéreas, cartas topográficas e dados gerados a partir de MNT como auxiliares na interpretação das cicatrizes de deslizamentos observadas nas imagens. As cicatrizes identificadas nas imagens e que se encontravam acessíveis (ao longo da Rodovia SP 99 e em pontos de fácil acesso) foram localizadas em trabalho de campo, com o auxílio de GPS, das cartas topográficas e da imagem analógica. As cicatrizes de difícil acesso foram mapeadas utilizando-se as fotografias aéreas como verdade terrestre, a partir das cicatrizes reconhecidas em campo e pelos elementos de interpretação. Foram utilizados pares estereoscópicos das fotografias aéreas na interpretação tanto das cicatrizes quanto de outros alvos, como feições antrópicas e de vegetação.

O trabalho de campo visou o reconhecimento da área de estudo e a observação de cicatrizes, feições antrópicas e feições relacionadas aos deslizamentos, tais como, taludes etc.

\section{RESULTADOS E DISCUSSÃO}

Os valores obtidos para a atenuação do espalhamento atmosférico confirmaram que as bandas mais afetadas por ele são aquelas da faixa do visível (TM 1, TM 2 e TM 3) prescindindo as demais deste pré-processamento. A imagem resultante desta correção, apesar da redução de sua média, não teve seu brilho muito afetado e, portanto, não se apresentou muito escura.

O erro obtido para o registro foi de 1,40 , considerado aceitável para áreas florestadas e de relevo acidentado, devido à dificuldade na obtenção de pontos de controle nestas áreas. Este erro também está dentro do limite aceitável considerando-se as escalas dos mapas e das imagens e a finalidade do trabalho (Netgis, 1997).

\section{Análise das imagens TM realçadas por ALC}

A técnica de ALC, aplicada nas bandas selecionadas para obter as composições coloridas, apresentou bons resultados, realçando de maneira geral as feições de interesse. Para as bandas 2, 3, 4, 5 e 7 de 1996 os limites máximos e mínimos de histograma utilizados foram, respectivamente: 15-44, 18-85, 4-105, 6-115, 2-63.

Pela análise da Tabela 1 verifica-se uma alta correlação entre as bandas TM 2 e TM7, TM 3 e TM 7 e TM 5 e TM 7 , enquanto entre as bandas TM 2 e TM 5, TM 4 e TM 7 e TM 3 e TM 4 há baixa correlação. As bandas TM 2, TM 3 e 
Tabela 1. Matriz de correlação - imagem TM.

\begin{tabular}{ccccccc}
\hline Bandas & $\mathbf{1}$ & $\mathbf{2}$ & $\mathbf{3}$ & $\mathbf{4}$ & $\mathbf{5}$ & $\mathbf{7}$ \\
\hline 1 & 1,000 & 0,853 & 0,784 & $-0,120$ & 0,277 & 0,543 \\
2 & 0,853 & 1,000 & 0,948 & 0,263 & 0,636 & 0,800 \\
3 & 0,784 & 0,948 & 1,000 & 0,274 & 0,697 & 0,877 \\
4 & $-0,120$ & 0,263 & 0,274 & 1,000 & 0,812 & 0,528 \\
5 & 0,277 & 0,636 & 0,697 & 0,812 & 1,000 & 0,895 \\
7 & 0,543 & 0,800 & 0,877 & 0,528 & 0,895 & 1,000 \\
\hline
\end{tabular}

TM 7 mostraram-se bastante apropriadas para a observação de feições antrópicas e de cicatrizes, conforme já indicado por Florenzano (1993). As composições coloridas com as bandas da faixa do visível e do infravermelho próximo e médio destacaram as características e diferenças entre as feições erosivas (cicatrizes), antrópicas e os setores cobertos por vegetação densa.

As composições coloridas TM 473 RGB e TM 572 RGB foram as que mais contribuíram para o realce tanto de feições de cicatrizes como antrópicas. Entretanto, a composição 473 RGB mostrou-se melhor para o destaque e discriminação de cicatrizes com diferentes características. Este resultado deve-se provavelmente ao fato de que o solo apresenta curva de reflectância ascendente a partir da banda 3 , tendo seu pico na banda 7 (Figura 3), possuindo estas duas bandas alta correlação. Observa-se, pela Tabela 1, que as bandas 3 e 7 têm pouca correlação com a banda 4 , o que proporciona um melhor contraste entre as áreas com e sem cobertura vegetal. Assim, a composição 473 RGB serviu de base para o mapeamento das cicatrizes e como referência na análise das imagens processadas por razão entre bandas e transformação por componentes principais.

As cicatrizes que aparecem em verde amarelado e amarelo nesta composição (Figura 4 - Anexo I), apresentam rocha exposta, o que foi verificado em campo e por fotografias aéreas coloridas, na escala de 1:5000. A análise da curva espectral realizada para estes pontos mostra altos valores de Números Digitais (NDs) a partir da banda TM 4, com pico na banda TM 5, decrescendo em direção à banda TM 7, como verificado na curva A da Figura 5.

Este comportamento é típico de rochas quartzosas, como o granito (Drury, 1993). Na área de estudo, tais afloramentos representam cicatrizes de deslizamentos, onde a rocha foi exposta. Um estudo mais detalhado das características das cicatrizes (se cobertas por vegetação ou se apresentam rocha de base exposta) pode indicar qual a situação desses pontos com relação aos deslizamentos, já que nos pontos onde há a presença de rocha, é possível que este tipo de processo possa se estabilizar (devido à ausência de regolito) ou surgirem outros tipos de processos, como a queda de blocos, que possuem extensão e magnitude diferentes de deslizamentos.

Algumas das cicatrizes revestidas por samambaia (ao longo da Rodovia SP 99) aparecem em magenta bem claro, e aquelas revestidas por gramíneas ou por samambaia de menor porte aparecem em cyan, tendendo a verde, o que pode indicar provavelmente uma maior integração da resposta do solo com a da vegetação. O perfil espectral extraído da cicatriz coberta por gramínea pode ser visto na Figura 5 (curva B), notando-se sua semelhança com a curva da vegetação.

As cicatrizes registradas na área de estudo aparecem sob forma elíptica, cônica ou irregular, o que está conforme a bibliografia consultada (Soares e Fiori, 1976; Zaruba e Mencl, 1982; Patton, 1988; IPT, 1989).

A Figura 6 (Anexo I) mostra uma cicatriz recente à data de obtenção da imagem, portanto não observada na fotografia aérea obtida no ano de 1994, relacionada provavelmente a deslizamento deflagrado pela elevada pluviosidade ocorrida no ano de 1996.

Esta cicatriz, que apresenta solo exposto e tem forma elíptica, inicia-se próxima à cabeceira e estende-se ao longo da linha de drenagem, características descritas na literatura para este tipo de feição (Soares e Fiori, 1976; Zaruba e Mencl, 1982; Patton, 1988; IPT, 1989). Foi possível pelo trabalho de campo observar outras feições detectadas nas imagens, como as rampas de tálus, samambaiais e gramíneas (capinzal) sobre cicatrizes de deslizamentos. As observações de campo garantiram maior segurança na interpretação das imagens e compreensão das variações de cor das composições coloridas realizadas. Através destas composições também foi possível a identificação de vales bem encaixados, onde se deposita material coluvial e tálus. Nas imagens analisadas não se verificaram variações de textura que pudessem ser atribuídas aos diferentes tipos de cobertura vegetal (como pinheiros, capoeiras e mata nativa). Nas fotografias aéreas, ao contrário, percebe-se alguns setores da vegetação que se apresentam com textura mais lisa que a predominante em outros setores. Esta variação pode ser devida à presença de capoeiras ou de pinheirais, necessitando-se de mais dados de campo para a sua explicação. Variações de textura que possam ser atribuídas a rupturas no dossel de- 


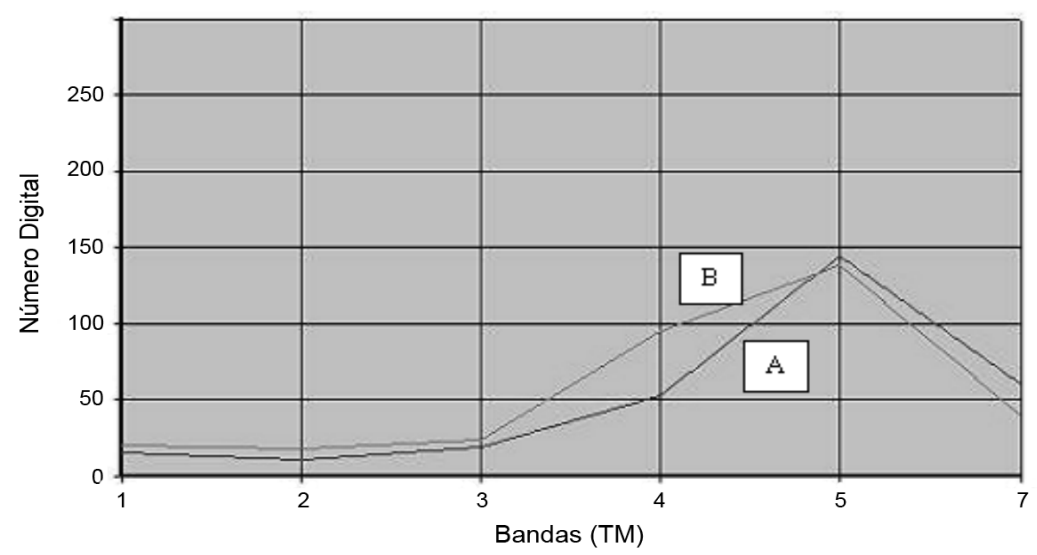

Figura 5. Perfis espectrais dos setores que apresentam rocha exposta $(A)$ e os revestidos por cobertura vegetal em (B).

vido ao afastamento das árvores, causadas por movimentos de massa não foram identificadas. Variações de densidade e de tipo de cobertura vegetal são perceptíveis nas imagens TM pela cor ou tonalidade, como ocorre nas cicatrizes onde a vegetação foi removida, apresentando solo ou rocha expostos ou colonização por samambaiais e gramíneas ou ainda áreas que apresentam rebrota (vegetação de porte arbustivo e/ou arbóreo).

\section{Razão entre bandas}

As imagens resultantes das operações de razão entre bandas destacaram feições antrópicas e de cicatrizes. A razão TM 4/3 e a imagem NDVI permitiram distinguir áreas com escassa vegetação daquelas completamente desprovidas de cobertura vegetal (conforme constatado em campo e por fotografia aérea). Os setores da cena com escassa cobertura vegetal, como aqueles referentes às cicatrizes, aparecem em tons de cinza médio escuros e os setores urbanizados ou de solos totalmente expostos como, por exemplo, áreas de empréstimo de areia, apresentam pixels cinza escuro. $\mathrm{O}$ resultado mais importante deste processamento foi o destaque de estradas e áreas desmatadas em geral, como ilustra a Figura 7 (Anexo II). A diferença entre as cicatrizes que se apresentam revestidas por samambaia ou capim e as que apresentam rochas expostas é percebida tenuamente. Nota-se uma gradual redução no brilho das primeiras áreas para as últimas. A não distinção entre áreas cobertas por samambaial das áreas cobertas por capinzal na imagem NDVI deve-se provavelmente à similaridade de resposta espectral destas, pois a razão entre bandas atenua as diferenças existentes entre alvos cujo comportamento espectral sejam semelhantes. Esta semelhança pode ser cau- sada pelo pouco vigor e pequeno porte da cobertura vegetal presente nos setores cobertos por estes tipos de vegetação e às características do solo. $\mathrm{O}$ mesmo ocorre para a composição 5/7 4/3 4/1 RGB com relação às cicatrizes que apresentam rocha exposta das que estão cobertas por capinzal. A diferença entre cicatrizes que apresentam rocha exposta e as cobertas por capinzal ou samambaial é melhor observada na composição 473 RGB, na qual estes alvos se distinguem pela cor. Ao analisar a Figura 5, observa-se semelhança no comportamento da curva espectral entre estes dois tipos de cicatrizes, pois ambas apresentam ascensão da curva a partir da banda 3 e declínio da banda 5 para a banda 7. Esta semelhança, como dito acima, é causada pelo fato da vegetação ser rala nessas áreas, tendo, portanto uma fração alta de solo na resposta que é integrada pelo sensor.

Com a composição 5/7 4/3 4/1 RGB foram obtidos resultados semelhantes ao do NDVI com relação ao destaque dos alvos de interesse (cicatrizes e feições culturais), porém, a distinção entre área urbana e as cicatrizes que apresentam rocha exposta e cobertas por samambaia é percebida pela diferença de matiz e cor (magenta escuro, magenta claro e cyan respectivamente) o que favorece visualmente a discriminação entre esses diferentes alvos em relação ao NDVI. Há semelhança na resposta entre as cicatrizes cobertas por capinzal e as que apresentam rocha exposta, como já citado.

\section{Transformação por Componentes Principais (TCP)}

Os resultados para a TCP mostraram que as primeiras bandas CPs estão livres de ruído e exibem de forma realçada os alvos que se mostram correlacionados nas bandas origi- 
nais antes de se efetuar este processamento.

A combinação das bandas geradas pela TCP proporcionou a discriminação de diferentes alvos, além da CP 1 manter a informação de textura. As CPs 5 e 6 não acrescentaram nenhuma contribuição à observação dos alvos de interesse, pois contêm basicamente apenas ruído.

A composição colorida CP 321 diferencia as cicatrizes que apresentam rochas expostas (cor magenta) das cicatrizes cobertas por gramíneas (azuladas), como pode ser verificado na Figura 8 (Anexo II). As áreas contendo solo exposto apresentaram confusão com as áreas urbanizadas.

\section{Resumo dos resultados}

Através das imagens obtidas pelos processamentos adotados foi possível identificar as feições relacionadas aos deslizamentos e localizar as cicatrizes em vários pontos da área de estudo. A interpretação das curvas de nível forneceu as formas de vertentes, o que reforçou a análise de contexto. O MNT também contribuiu para uma melhor análise da posição, nas vertentes, onde ocorrem as cicatrizes e, portanto, para uma identificação mais precisa dessas.

Com relação à caracterização das cicatrizes, foi possível identificar quatro tipos, os quais apresentam respostas diferenciadas nas imagens conforme descritos a seguir (Sestini, 1999):

Tipo 1. cicatrizes com solo exposto: resposta do solo, cuja reflectância sofre variação conforme o tipo de solo, quantidade de umidade deste etc. Este tipo é melhor discriminado na composição TM 473 RGB;

Tipo 2. cicatrizes cobertas por samambaia ou gramíneas: a resposta deste tipo de cicatriz na imagem é fortemente relacionada ao solo, já que a fração deste é alta, devido à escassez da cobertura vegetal, entretanto, contém pixels "contaminados" pela resposta da vegetação, sendo discriminado nas composições TM 473 RGB, CP 321 e 5/7 4/3 4/1 RGB. Nas imagens $4 / 3$ e NDVI este tipo apresenta resposta semelhante ao tipo 4;

Tipo 3. cicatrizes cobertas por vegetação densa (capoeira etc.): devido ao porte e a fração de cobertura vegetal serem mais expressivos que no tipo 2 , há resposta mais acentuada desta, podendo, conforme o grau de regeneração da mesma, recobrir a cicatriz e inviabilizar sua detecção direta por dados TM Landsat;

Tipo 4. cicatriz com rocha exposta: resposta da rocha, que pode sofrer variação conforme tipo de litologia, características estruturais e grau de intemperismo. Foi bem discriminado nas composições TM 473 RGB, CP 321 e 5/7 4/3 4/1 RGB.
Estas informações podem subsidiar a definição de áreas estáveis e áreas de recorrência de deslizamentos, bem como o cálculo desta recorrência (estudos multitemporais, tanto com dados de sensoriamento remoto como através de relatórios, boletins da defesa civil etc.). Elas também podem servir de base para um mapeamento de diferentes processos (movimentos lentos a rápidos) quando integradas com dados de MNT, solo, vegetação etc. Por exemplo, locais com declividade acentuada e rocha exposta por deslizamentos podem ser áreas de ocorrência de quedas de blocos, devido a fatores estruturais (cisalhamentos) e exógenos (ação de termoclastia ou intemperismo químico devido às características climáticas).

Além das cicatrizes, foi possível identificar também feições como rampas de tálus, resultantes do transporte do material por deslizamentos e feições antrópicas que provocam ou aceleram os processos de deslizamentos.

O mapeamento das cicatrizes, a caracterização dessas, bem como o das feições descritas acima, servem como auxílio na criação de modelos destinados a representar os processos relacionados a movimentos de massas e gerar previsão de seus tipos, bem como servir para calibração de modelos de previsão de áreas de risco.

\section{CONCLUSÃO E RECOMENDAÇÕES}

Os dados TM Landsat possibilitam observar as feições de cicatrizes e contribuíram na detecção de pontos favoráveis aos deslizamentos.

Constatou-se, ainda, que um único tipo de processamento é insuficiente para o realce de todas as feições relacionadas a deslizamentos, bem como a necessidade de se utilizar dados de sensores com resoluções espacial, espectral, radiométrica e temporal mais finas. Neste sentido, novos sensores orbitais que estão sendo desenvolvidos dotados de melhor resolução oferecem boas perspectivas aos estudos relacionados aos movimentos de massa. Assim, para imagens obtidas por sensores hiperespectrais, recomenda-se testar a transformação da imagem de 1996 em imagem reflectância para uma melhor avaliação de quais bandas podem ser utilizadas nestes tipos de sensores para efetuar a razão, visando o realce de diferentes situações (cicatrizes com rocha exposta, solo exposto, cobertas por vegetação etc.). Também recomenda-se testar o modelo de mistura para esta finalidade, inclusive em dados multiespectrais.

Recomenda-se testar a integração de fotografias aéreas e imagens TM, observando-se a maior proximidade possível da data e do horário da obtenção de ambos, considerando-se os problemas decorrentes da topografia e geometria de aquisição (sombreamento etc.). 


\section{ANEXO I}

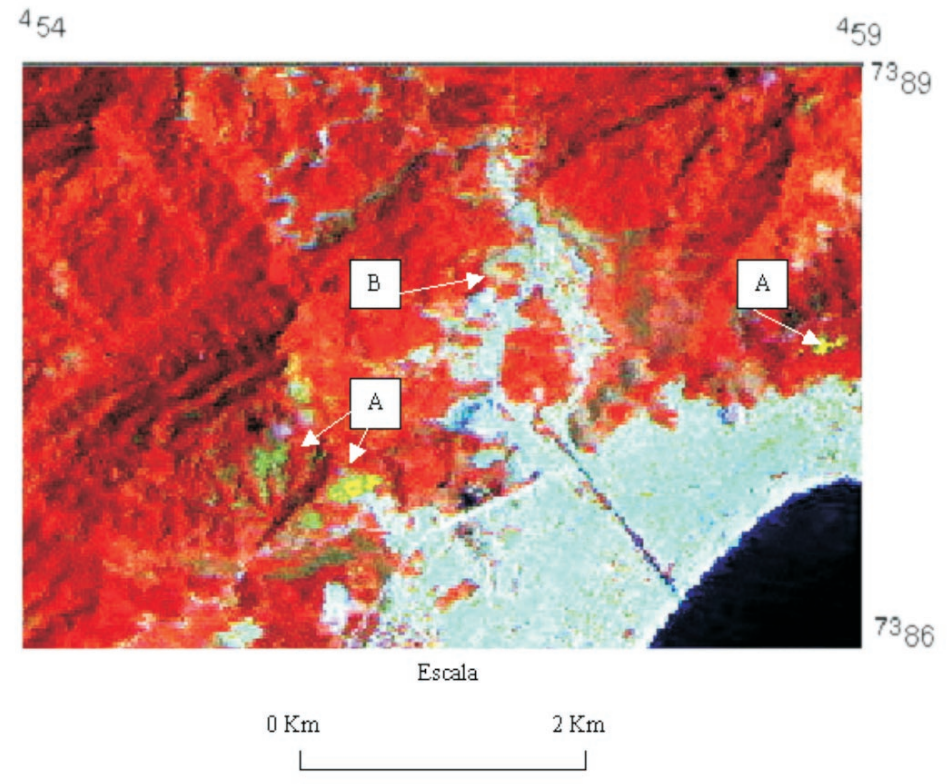

Figura 4. Cicatrizes apresentando rocha exposta (A) e cobertura de gramínea (capinzal) (B), composição colorida TM473-RGB.
Figura 6. Composição colorida TM, 473 RGB, ano de 1996 e fotografia aérea vertical pancromática, obtida em 1994, do mesmo local. Notar a presença de cicatriz provocada por deslizamento ao longo da drenagem na imagem e ausência desta na fotografia aérea.

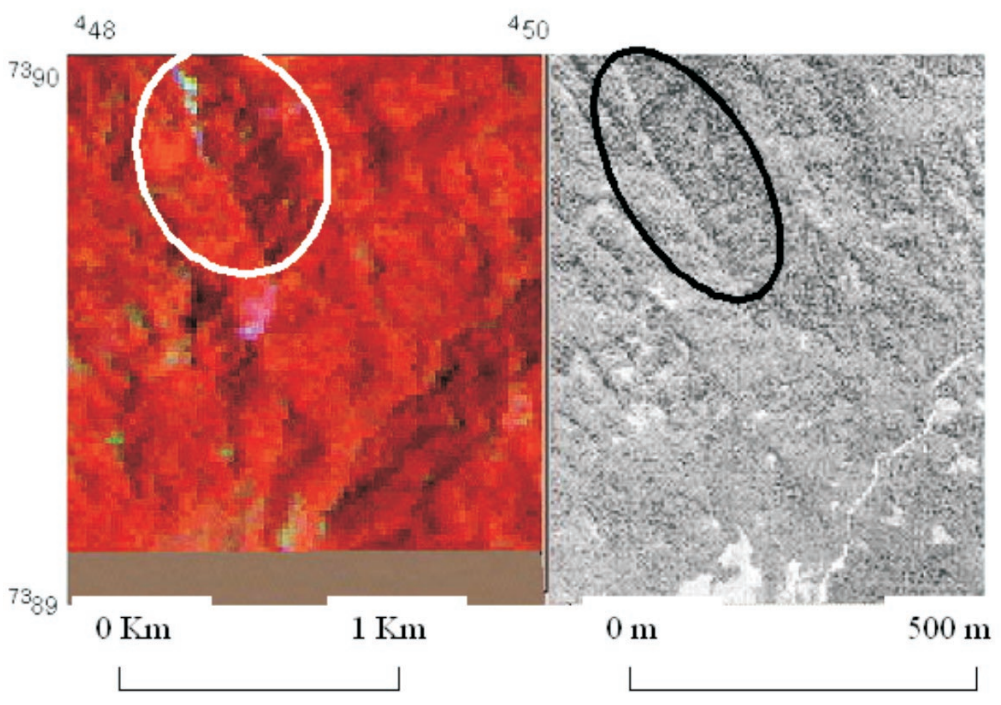



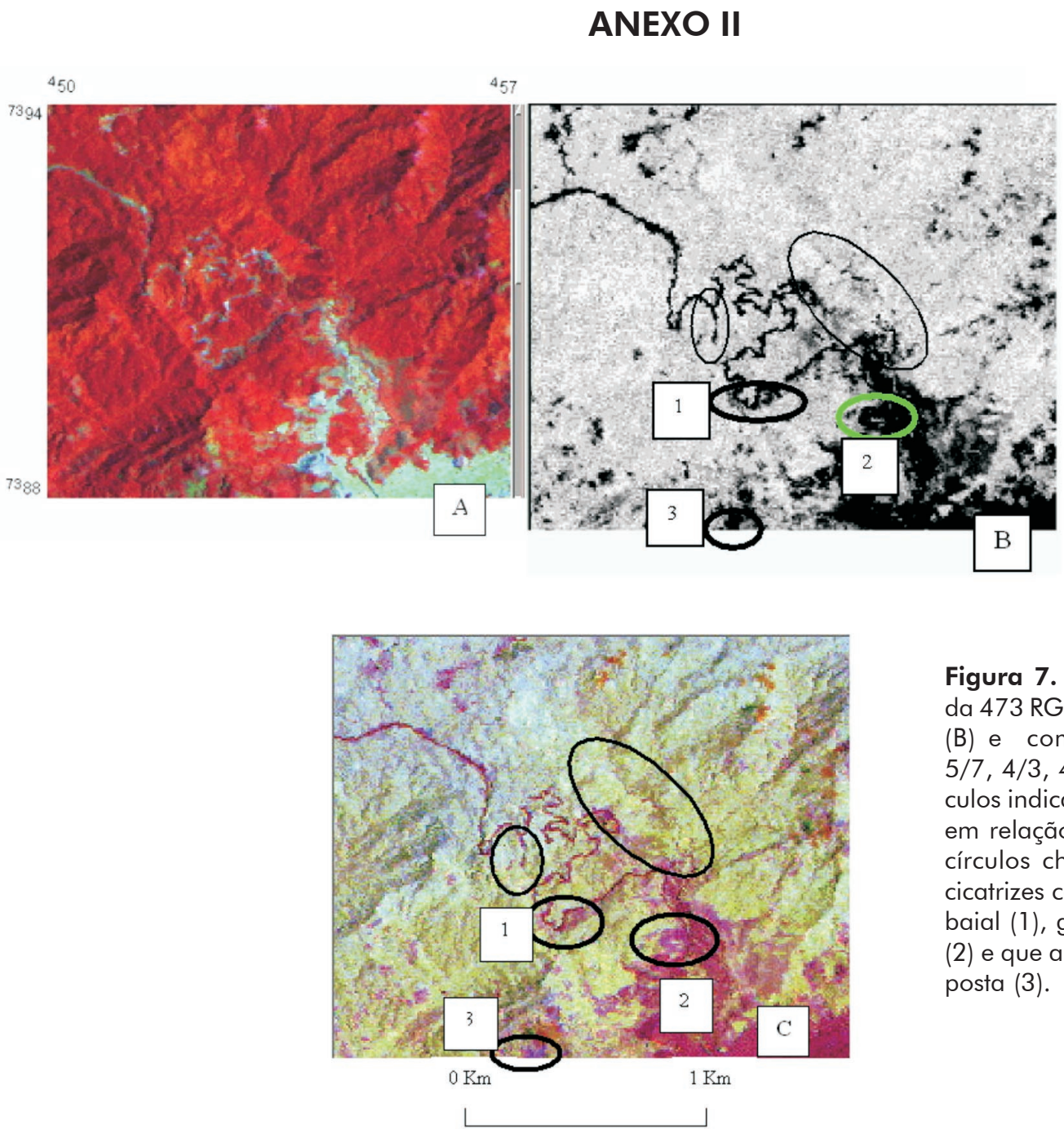

Figura 7. Composição colorida 473 RGB, (A); imagem NDVI (B) e composição colorida 5/7, 4/3, 4/1 RGB (C). Os círculos indicam alvos destacados em relaçãa à composição. Os círculos cheios em $B$ indicam cicatrizes cobertas por samambaial (1), gramíneas (capinzal) (2) e que apresentam rocha exposta (3).

Figura 8. Composição colorida CP 321 (RGB), distinguindo cicatrizes com rocha exposta $(A)$ da coberta por capim (B), a qual apresenta pixels de cor azul.

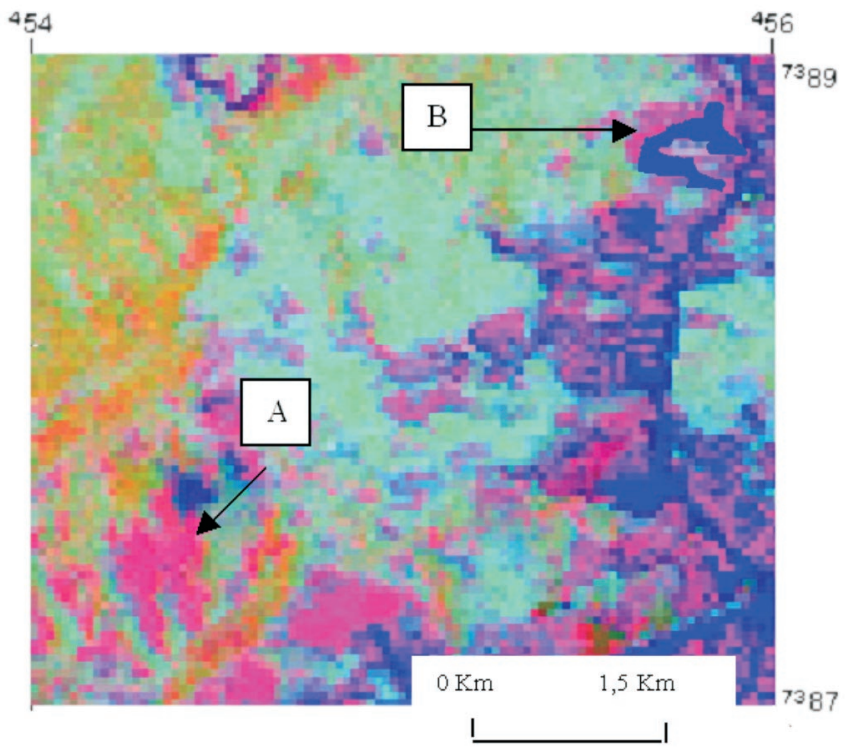




\section{REFERÊNCIAS BIBLIOGRÁFICAS}

AB'SABER, A. N. O domínio dos mares de morros no Brasil. Geomorfologia. São Paulo, n. 2, p. 1-9, 1966.

ALMEIDA, F. F. M. Os fundamentos geológicos do relevo paulista. Boletim do Instituto Geográfico e Geológico do Estado de São Paulo, São Paulo, v. 41, p. 167-262, 1964.

AUGUSTO FILHO, O. Cartas de risco de escorregamento: uma proposta metodológica e sua aplicação no município de Ilhabela, SP. 1994. 172 f. Dissertação (Mestrado) - Escola Politécnica, Universidade de São Paulo, São Paulo.

BELCHER, D. J. Soils. In: PHILIPSON, W. R. Manual of photographic interpretation. Maryland: American Society for Photogrammetry and Remote Sensing, 1997. p. 167-224.

BERGER, A. R. Geoindicator checklist. In: BERGER, A. R.; IAMS, W. J. Geoindicators: assessing rapid environmental changes in Earth systems. Rotterdam: Balkema, 1996. p. 395-454.

BOWKER, D. E. et al. Spectral reflectance of natural targets for use in remote sensing. Washington DC: NASA, 1985. 185 p. (NASA - RP-1139).

CENTRO TECNOLÓGICODE HIDRÁULICA (CTH) Dados de precipitação dos postos E2-046 e E2-128. São Paulo: CTH, 1997.

CROSTA, A. P. Processamento digital de imagens de sensoriamento remoto. Campinas: Universidade de Campinas, $1993.170 \mathrm{p}$.

CRUZ, O. A Serra do Mar e o litoral na área de Caraguatatuba - SP: contribuição à geomorfologia litorânea costeira tropical. 1974. 181 f. Tese (Doutorado) - Faculdade de Filosofia Letras e Ciências Humanas, Depto Geografia, Universidade de São Paulo, São Paulo.

DIKAU, R. Derivatives from detailed geoscientific maps using computer methods. Zeitschrift für Geomorphologie, Supplementband, Frankfurt, v. 2, p. 45-55, 1990.

DRURY, S. A. Image interpretation in Geology. London: Chapman e Hall, 1993, 290 p.

FERNANDES, N. F; AMARAL, C. P. Movimentos de massa: uma abordagem geológico-geomorfológica. In: GUERRA A. J. T.; CUNHA S.(Eds.) Geomorfologia e meio ambiente. Rio de Janeiro: Bertrand Brasil, 1996. p. 123-194.

FLORENZANO, T. G. Unidades geomorfológicas da região sudeste (SP) identificadas por imagens de satélites. 1993. 164 f. Tese (Doutorado) - Faculdade de Filosofia Ciências Humanas e Letras, Depto Geografia, Universidade de São Paulo, São Paulo.
GAO J.; LO, C. P. Micro-scale modelling of terrain susceptibility to landsliding from a DEM: a GIS approach. Geocarto International. Hong Kong, v. 10, n. 4, p. 15-30, 1995.

HANSEN, M. J. Strategies for classification of landslides. In: BRUNSDEN, D.; PRIOR, D. B. (Eds.) Slope instability. Salisbury: John Wiley e Sons, 1984. p. 1-25.

INSTITUTO DE PESQUISAS TECNOLÓGICAS (IPT). Estudo das instabilizações de encostas da Serra do Mar na região de Cubatão objetivando a caracterização do fenômeno "corrida de lama" e prevenção de seus efeitos. São Paulo: IPT, 1989. 185 p. (Relatório n. 26258).

KING C.; DELPONT G. Spatial assessment of erosion: contribution of remote sensing, a review. Remote Sensing Review, v. 7, p. 223-232, 1993.

LILLESAND, T. M.; KIEFER, R. W. Remote sensing and image interpretation. New York: John Wiley e Sons, 1994. $750 \mathrm{p}$.

MATHER, P. M. Computer processing of remotely sensed images: an introduction. New York: John Wiley e Sons, 1987. $352 \mathrm{p}$.

MCDERMID G. J.; FRANKLIN, S. Spectral, spatial and geomorphometric variables for the remote sensing of slope processes. Remote Sensing of Environment, New York, v. 49, p. 57-71, 1994.

MCKEAN, J.; BUECHEL, S.; GAYDOS, L. Remote sensing and landslide hazard assessment. Photogrammetric Engineering e Remote Sensing, Maryland, v. 57, n. 9, p. $1185-1193,1991$.

NETGIS. SPRING 2.0: Sistema de Processamento de Informações Georreferenciadas. v. 2: Processamento de imagens. São José dos Campos: Netgis, 1997.

NOVO, E. M. L. Sensoriamento remoto: princípios e aplicações. São Paulo: Edgard Blücher, 1992. 308p.

NUNES, L. H.; MODESTO, R. P. Comportamento pluviométrico nos municípios atendidos pelo plano preventivo de defesa civil-PPDC. Revista do Instituto Geológico, São Paulo, v. 13, n. 1, p. 47-57, 1992.

NUNES, L. H.; MODESTO, R. P. Pluviometria e problemas ambientais no município de Guarujá. Revista do Departamento de Geografia. São Paulo, v. 10, p. 59-72, 1996.

OKIDA, R. Técnicas de sensoriamento remoto como subsídio ao zoneamento de áreas sujeitas a movimentos gravitacionais de massa e a inundações. 1996. $125 \mathrm{f}$. Dissertação (Mestrado) - Instituto Nacional de Pesquisas Espaciais, São José dos Campos.

PATTON, P. C. Drainage basin morphometry and floods. In: BAKER, V. R.; KOCHEL, R. C.; PATTON, P. C. Flood Geomorphometry. New York: Wiley, 1988. p. 51-65.

PROJETO RADAMBRASIL. Folhas SC-32 Rio de Janeiro/ Vitória: geologia, geomorfologia, pedologia, vegetação, 
uso potencial do solo, levantamento de recursos naturais. Rio de Janeiro: Ministério das Minas e Energia, $1983.775 \mathrm{p}$.

RICHARDS, J. A. Remote sensing digital image analysis: an introduction. Berlin: Springer-Verlag, 1995.340 p.

ROMANOVSKII, N. V. et al. Periglacial processes as geoindicators in the cryolithzone. In: BERGER, A. R.; IAMS, W. J. (Eds.) Geoindicators: assessing rapid environmental changes in earth systems. Rotterdam: Balkema, 1996. p. 47-68.

RYDÉN, A. Approaches to practical remote sensing for environmental studies: experiences from a case study in Swaziland and southern Mozambique. ITC Journal. Enschede, v. 2, p. 136-145, 1997.

SCHOWENGERDT, R. A. Techniques for image processing and classification in remote sensing. Orlando: Academic Press, $1983.249 \mathrm{p}$.

SESTINI, M. F. Variáveis geomorfológicas no estudo de deslizamentos em Caraguatatuba - SP utilizando imagens TM-Landsat e SIG. 1999. 140 f. Dissertação (Mestrado) - Instituto Nacional de Pesquisas Espaciais, São José dos Campos.

SOARES, P. C.; FIORI, A. P. Lógica e sistemática na análise e interpretação de fotografias aéreas em Geologia. Notícia Geomorfológica, v. 16, n. 32, p. 71-103, 1976.

VALÉRIO FILHO, M.; PINTO, S. A. F. Resultados preliminares da utilização de imagens TM Landsat na identificação de áreas submetidas a processos de erosão. São José dos Campos: INPE, 1986. 26 p.

VENEZIANI, P.; ANJOS, C. E. Metodologia de interpretação de dados de sensoriamento remoto e aplicações em Geologia. São José dos Campos: INPE, 1982, 54 p.

VERSTAPPEN, H. The Remote sensing in Geomorphology. Amsterdam: Elsevier, 1977. 214 p.

WALSH, S. J.; BUTLER, D. R. Morphometric and multispectral image analysis of debris flow for natural hazard assessment. Geocarto International, Hong Kong, v. 12, n. 1, p. 59-70. 1997.

WALSH, S. J.; BUTLER, R.; MALANSON, G. P. An overview of scale, pattern, processes relationships in Geomorphology: a remote sensing and GIS perspective. Geomorphology, Amsterdam, v. 21, n. 3 - 4, p. 183-205, 1998.

ZARUBA, Q.; MENCL, V. Landslides and their control: development in geotechnical engineering. Amsterdam: Elsevier, $1982.324 \mathrm{p}$. 